\title{
O IMPROVÁVEL NA AULA DE HISTORIA: SOCIABILIDADES, RACIALIDADES E MODOS DE ESTAR JUNTO NA ESCOLA
}

THE IMPROBABLE IN HISTORY CLASS: SOCIABILITIES, RACIALITIES AND WAYS OF BEING TOGETHER IN SCHOOL

\author{
LO IMPROBABLE EN LA CLASE DE HISTORIA: SOCIABILIDADES, RACIALIDADES \\ Y MODOS DE ESTAR JUNTOS EN LA ESCUELA
}

Carla Beatriz Meinerz carlameinerz@gmail.com

Flávia Eloisa Caimi caimi.flavia@gmail.com

Sandra Regina Ferreira de Oliveira \begin{abstract}
sandraoliveira.uel@gmail.com
REVISTA PEDAGÓGICA

Revista do Programa de Pós-graduação em Educação da Unochapecó | ISSN 1984-1566

Universidade Comunitária da Região de Chapecó | Chapecó-SC, Brasil Como referenciar este artigo: MEINERZ C. M.; CAIMI, F. E.; OLIVEIRA, S. R. F. O Improvável na Aula de História: sociabilidades, racialidades e modos de estar junto na escola. Revista Pedagógica, Chapecó, v. 20, n. 45, p. 53-72, set./dez. DOI: http://dx.doi.org/10.22196/rp.v20i45.4486
\end{abstract}

RESUMO: O artigo resulta de uma reflexão compartilhada no campo da Pesquisa em Educação e almeja interseccionar as categorias sociabilidade e racialidade na análise das relações estabelecidas nas instituições escolares. Enfoca a escola como espaço complexo de construção de modos de estar junto, ambiente marcado por uma ecologia de distintos saberes. O ensino de história, como lócus da instituição escolar, é abordado como lugar do improvável. Ao enfocar a aula de história, destacamos experiências que oscilam desde um possível compartilhamento das diferenças até a sua negação. Tal negação pode revelar situações e atores sociais ignorados ou trivializados em suas relações cotidianas. Propõe a análise de situações improváveis no cotidiano escolar como método diferenciado de análise investigativa. Os resultados parciais das pesquisas em questão se produzem no movimento de questionamento epistemológico e pedagógico provocado pelo pensamento decolonial.

Palavras-chave: Escola. Ensino de História. Sociabilidade. Racialidade. Decolonialidade.

ABSTRACT: The article results from a shared reflection in the field of Research in Education and aims to intersect the categories sociability and raciality in the analysis of relationships established in school institutions. It focuses the school as a complex space of construction of ways of being together, environment marked by an ecology of different knowledges. The teaching of history, as the locus of the school institution, is approached as a place of the improbable. In focusing on history class, we highlight experiences that range from a possible sharing of differences to their negation. Such denial can reveal situations and social actors ignored or trivialized in their daily relationships. It proposes the analysis of improbable situations in school everyday as a differentiated method of investigative analysis. The partial results of the researches in question take place in the movement of epistemological and pedagogical questioning provoked by the decolonial thought.

Keywords: School. Teaching History. Sociability. Raciality. Decoloniality.

RESUMEN: El artículo resulta de una reflexión compartida en el campo de la Investigación en Educación y anhela interseccionar las categorías sociabilidad y racialidad en el análisis de las relaciones establecidas en las instituciones escolares. Enfoca la escuela como espacio complejo de construcción de modos de estar juntos, ambiente marcado por una ecología de distintos saberes. La enseñanza de historia, como locus de la institución escolar, viene abordada como lugar de lo improbable. Al enfocar la clase de historia, destacamos experiencias que oscilan desde un posible compartir diferencias hasta la negación de las mismas. Tal negación puede revelar situaciones y actores sociales ignorados o trivializados en sus relaciones cotidianas. Propone el análisis de situaciones improbables en el cotidiano escolar como método diferenciado de análisis investigativo. Los resultados parciales de las investigaciones en cuestión se producen en el movimiento de cuestionamiento epistemológico y pedagógico provocado por el pensamiento decolonial.

Palabras clave: Escuela. Enseñanza de Historia. Sociabilidad. Racialidad. Descolonialidad. 


\section{Considerações Iniciais: os improváveis na cultura escolar}

Era difícil, talvez não surpreendentemente naquele dia, observar as fronteiras, ver $e$ desver apenas o que eu deveria... [...] $O$ resto eu ignorei ou tentei. (MIÉVILLE, 2014, p. 46).

China Miéville (2014), em seu livro A Cidade \& A Cidade, nos leva a percorrer as ruas de Beszél e UI Quoma, nações diferentes que dividem o mesmo espaço geográfico de uma cidade. Na bolha suspensa da ficção, onde tempos e espaços são reconfigurados, é possível elaborar e responder perguntas que suscitam um processo reflexivo sobre o mundo, sobre o outro e sobre nós mesmos. As questões propostas por Miéville, em meio a uma complexa trama desencadeada por um crime, nos desafiam a pensar as fronteiras que delimitam os espaços que julgamos conhecer e desnuda nosso olhar, provocando-nos a compreender o desver como recurso afetivo e cognitivo capaz de tensionar as relações de sociabilidade que se efetivam nos espaços de convivência constituídos na instituição escolar.

No processo de apreensão das coisas do mundo, aprender a ver ou, mais precisamente, aprender a selecionar o que pode ser visto e o que deve não ser visto, é um processo no qual o sujeito está inserido desde os primeiros instantes de vida. Essa aprendizagem varia conforme o contexto sociocultural e a cosmosensação em que se desenvolve. Tomamos de empréstimo o conceito de cosmosensação, como alternativa à ideia de cosmovisão, a partir dos estudos do filósofo Fernando Noguera (2017), fundamentados na pensadora nigeriana Oyeronke Oyewumi, para referirmos formas de viver, explicar e sentir o mundo, capazes de incorporar todos os sentidos da singularidade humana, inclusive na relação com os demais seres do universo. Voltando ao campo da ficção, as crianças de Beszél e UI Quoma precisam aprender a desver as pessoas e as coisas da outra cidade como aspecto constituinte de sua identidade e para preservarem suas próprias vidas.

O espaço de transgressão possibilitado pela ficção nos faz imaginar a escola e seus ensinamentos para o aprender a desver: desver o quê e por quê? Desver os rituais da gramática escolar (BENITO, 2017), com sua materialidade expressa em horários, regramentos, manuais didáticos, proposições curriculares, ressaltando as sociabilidades experimentadas em recepções, apropriações, acomodações e resistências aos mesmos.

Particularmente em nossa escrita, desver significa quebrar os silêncios sobre as formas de apropriação e resistência aos ritos que destacam, em geral, objetos e atores de um espaço compreendido apenas como lugar de transmissão de saberes cientificamente sistematizados. Neste 
ensaio, proporemos desver experiências categorizadas como improváveis, desenvolvidas em espaços-tempos constituídos na cultura escolar (GIMENO SACRISTÁN, 2000), protagonizadas em escolas públicas brasileiras, compreendidas como rompimentos dos prováveis estabelecidos na gramática escolar (BENITO, 2017).

O que chamamos de improvável aparece em duas experimentações, que se tornaram campo de estudos na pesquisa em Educação: a primeira reconstrói um episódio, marcado pelo sofrimento de uma criança negra, desencadeado a partir da leitura de um livro didático numa aula de história; a segunda ressignifica relatos de estudantes e educadores, convidados a selecionar positividades de seus espaços escolares, em geral marcados pela reincidência de narrativas de negatividade, descrença e desvalorização. Em comum, temos o foco nas sociabilidades instituídas em experiências escolares. Destaca-se que são problemas de pesquisa situados no contexto das escolas públicas brasileiras da região sul do País, estado do Paraná. Como diferença, destacamos analiticamente o fato de que essas experiências podem ser marcadas por distintas sensibilidades, que oscilam do sofrimento imposto pela discriminação racial até as alegrias expressas pelos afetos positivados em situações de aprendizagem.

A seguir, resumimos cada investigação, destacando o improvável em cada uma delas.

A primeira situação resulta de um trabalho de pós-doutoramento (2017-2018), vinculado especificamente ao ensino de História, em sua consecução experiencial numa aula, ou seja, no espaço mais concreto da realização do ato educativo escolarizado. Trata-se do estudo de uma situação emblemática concernente a uma família negra que busca auxílio judicial, após o filho de onze anos negar-se a ir para a escola no dia em que deveria ler trechos de um livro didático, cuja temática era o racismo na sociedade brasileira. Ocorreu numa escola estadual da cidade paranaense de Campo Mourão, no ano de 1997. Nas páginas do livro, sob o título $O$ racismo na tradição cultural do Brasil, constava uma atividade de leitura e interpretação de versinhos, quadrinhas e provérbios recolhidos em pesquisa do sociólogo Florestan Fernandes, nos anos de 1960. Destacamos dois exemplos desses versinhos e quadrinhas:

[...] O negro é burro de carga

O branco é inteligente;

O branco só não trabalha, Porque preto não é gente. [...] Negro preto, cor da noite Cabelo de pixaim

Pelo amor de Deus, te peço:

Negro não olhe para mim. (MACEDO; OLIVEIRA, 1996, p. 80-81).

Ao então menino, único negro em sua sala, fora dada a tarefa de ler e apresentar tais registros aos colegas, numa 
aula de História. Os versinhos, segundo relatos da família, foram repetidos por colegas, em distintos espaços e situações de sociabilidade, após a professora solicitar a sua leitura. Choroso e desejoso de não viver tal situação, o menino anuncia para a família que não quer mais ir para a escola. Pai e tio decidem procurar o Fórum da cidade. Tais versinhos, quadrinhas e provérbios causaram simultaneamente outro processo judicial, através de ação empreendida pelos movimentos sociais organizados - o Movimento Negro e a Seção do Sindicato dos Professores, na Comarca de Maringá.

O que é improvável nessa situação? Uma criança, em sofrimento por discriminação racial, resiste ao pedido de realizar uma tarefa solicitada pela professora e toma a atitude, apoiada pela família, de nunca mais voltar ao ambiente escolar.

A segunda cena investigativa resulta de um projeto mais abrangente acerca do vivido dentro e fora da sala de aula, considerando as múltiplas possibilidades contidas nas experiências escolares. Trata-se de pesquisa realizada no período de 2011-2014, que tem na categoria do improvável um ponto de partida, na medida em que propõe questões para alunos e professores pensarem e relatarem suas experiências escolares positivadas. O projeto, intitulado HISPED - Histórias de sucesso pedagógico, teve a sua primeira etapa realizada em dez escolas da cidade de Londrina, estado do Paraná, com alunos e professores do primeiro ao nono ano do ensino fundamental. A segunda etapa foi realizada com professores de cinco escolas, nas cidades de Londrina, Rio de Janeiro, Aracaju, Palmas e Campo Grande. Na primeira etapa, foram recolhidos nas escolas, por meio de uma caixa coleta, mais de oito centenas de relatos nos quais os alunos, em ampla maioria, e alguns professores, contavam suas experiências positivas na escola. Na segunda etapa, em cada escola, realizou-se um grupo focal no qual os professores tomavam conhecimento dos conteúdos dos relatos dos alunos e avançavam na reflexão sobre o que é e como se efetiva uma situação de sucesso escolar. A análise de tais relatos propiciou tecer reflexões, dentre outras questões, sobre as relações com o saber que são estabelecidas pelos alunos e pelos professores.

A ideia para desenvolvimento de tal projeto foi gestada num contexto de angústia diante do descrédito de professores, pesquisadores, pais, comunidades e mídias sociais, frente à qualidade do ensino ofertado pelas escolas públicas. Os relatos dos alunos, na forma escrita e em desenhos, são pequenas histórias que, em sua simplicidade, descortinam o cenário da sala de aula, revelando aspectos considerados importantes para a realização de processos de aprendizagens satisfatórios. A partir dos relatos, conclui-se que uma experiência de sucesso na escola, na visão dos alunos, é aquela que incita e valoriza as relações humanas desenvolvidas em diferentes espaços (para além da sala de aula) e de diferentes formas, nas quais o professor 
assume a responsabilidade de ensinar conhecimentos que possibilitam compreender os problemas atuais.

O improvável no cotidiano escolar é aqui consolidado como categoria analítica. As pesquisas acima apresentadas situam-se no campo do improvável (LAHIRE, 1997), pois trabalham com situações nas quais as estruturas rígidas da gramática escolar se dissolvem e, por vezes, as relações de poder se desequilibram. A partir desses modos improváveis de se apropriar do que seja ensinar e aprender, tendo o estar junto como catalisador e difusor dos processos de sociabilidade, revelam-se situações e atores sociais ignorados ou trivializados em suas relações cotidianas. Estabelece-se um efetivo diálogo sobre o que compõe e define a escola como espaço complexo de construção de modos de estar junto (PUNTA, 2016), portanto, propiciadora da aprendizagem do desver, demandada por suas contradições e necessidade de fazer escolhas. Ainda que todos vejam o que importa ser ensinado, o aluno apontado como aquele que tem dificuldade em aprender e se adaptar, assim como a criança alvo de discriminação racial, são os atores que nos dão pistas de resistência ou de outras maneiras de se praticar a escola.

A escolha por uma situação improvável como campo de investigação, em nossa compreensão, é possível ao conceber a escola como um ambiente marcado por uma ecologia de distintos saberes que se ramificam de diferentes formas nas vidas dos sujeitos. O conceito de ecologia, aqui compreendido a partir de Boaventura de Sousa Santos (2002), se opõe à ideia de práticas hegemônicas e aponta para a multiplicidade existente quando o olhar é conduzido por lógicas não excludentes. São diversas as ecologias nomeadas pelo autor, e o que se encontra em comum entre todas é a necessidade posta de dialogar com o nosso desver e ir além do que se define, em uma primeira instância, como realidade. Santos (2002) nomeia como exemplos os saberes construídos pelos movimentos sociais e pelas comunidades com as quais dialogamos em nossas pesquisas, proclamados por pessoas indígenas, negras, mulheres, igualmente por jovens ou educadores. Para o autor, "[...] trata-se de uma versão ampla do realismo, que inclui as realidades ausentes por via do silenciamento, da supressão e da marginalização, isto é, as realidades que são ativamente produzidas como não existentes" (SANTOS, 2002, p. 253). O reconhecimento dessa ecologia de saberes está em relação com o questionamento do pensamento abissal e das suas práticas de poder correlatas (SANTOS, 2010). Assume-se que todo conhecimento é interconhecimento, declara-se como inesgotável a diversidade epistemológica do mundo e reconhece-se que o conhecimento científico é uma tipologia dentre tantas outras formas de conhecimento. Para o autor,

É próprio da natureza da ecologia de saberes constituir-se mediante perguntas constantes e respostas incompletas. Aí 
reside sua característica de conhecimento prudente. A ecologia de saberes nos capacita a uma visão mais abrangente tanto daquilo que conhecemos como daquilo que desconhecemos, e também nos previne de que aquilo que não sabemos é ignorância nossa e não ignorância em geral. (SANTOS, 2010, p. 94).

A escola, a partir do postulado da ecologia de saberes, não é um espaço que pode ser pensado confortavelmente. O espaço escolar é, ou deveria ser, um espaço no qual se corre riscos (RATTERO, 2013). Não há escolhas certeiras por caminhos previsíveis e roteirizados quando a meta é aprender a viver e aprender a viver junto com o outro. É exterior a tudo o que se passa naquele lugar. Sem afetar, sem afetos (RATTERO, 2013). Há outros tipos de conteúdos que trazem o inesperado, que se rompem em perguntas sequer dantes pensadas. Perguntar por situações improváveis pode inverter a ordem e descoloniza a relação pedagógica esperada para uma escola.

Ao considerar o improvável e o estar juntos como redes complexas que sustentam a construção de múltiplos saberes, nos deparamos com o aspecto de que o improvável brota de muitas variáveis. Em geral, tem a marca do corpo que não se adapta à cultura escolar e se expressa por formas que variam do sofrimento ao afeto baseado no bem viver. Segundo David Choquehuanga (2010), o Bem Viver fundamenta sistemas de vida de povos indígenas da América Latina, alicerçando-se sobre princípios como reciprocidade entre as pessoas, amizade fraterna e convivência com outros seres vivos. De qualquer forma, em ambos os casos, é preciso considerar a escola como espaço de buscas coletivas (PUNTA, 2016).

O improvável nos coloca frente à situação de positividades e, por vezes, nos faz deparar com cenários carregados de negatividade. Por qualquer caminho, escolher o improvável como categoria de pesquisa nos leva a adentrar em outros desenhos em um micro espaço que se forma dentro desse espaço maior que chamamos escola. Pesquisas que recortam aspectos que, de uma forma ou outra, buscam compreender movimentos e/ou grupos de pessoas que rompem com o convencional, com a rotina, são um caminho promissor por se pensar a escola a partir de uma perspectiva da decolonialidade.

Por meio de uma investigação realizada em escolas francesas, Bernard Lahire (1997) coloca em questionamento a ideia de que crianças oriundas de famílias de baixa renda apresentam mais dificuldades na aprendizagem da leitura e da escrita. Escolheu a categoria do improvável ao colocar como objetivo de pesquisa enfrentar o desafio sociológico de trabalhar na "[...] tentativa de compreensão de situações atípicas, que não nos mostram aquilo que poderíamos esperar" (LAHIRE, 1997, p. 12). Para isso, direcionou o olhar para as crianças que, mesmo em situações 
adversas, apresentam um bom resultado de aprendizagem. $\mathrm{O}$ autor, todavia, não realizou a pesquisa somente com estas, pois era preciso compreendê-las na relação com um grupo invisível, que se constitui na cultura escolar: as crianças de famílias de baixa renda. Lahire selecionou um grupo de famílias com configuração familiar e condições econômicas e culturais semelhantes e se dispôs a estudar a relação que se estabelece entre tais configurações familiares e o universo escolar por meio do estudo de crianças com diferentes desempenhos escolares. Lahire assume a posição de que a sociologia "[...] pode ajudar a compreender casos específicos (não especialmente no sentido de 'excepcionais') sem dispensar as razões ou disseminar as causas ao infinito" e compreende esses casos como um espaço, como um elo "[...] entre o senso comum e o saber científico que, dados os problemas epistemológicos, metodológicos e teóricos levantados pela pesquisa, complica de maneira singular o debate sobre o tema" e sua aposta vai, nas trilhas de uma antropologia de interdependência, pela escolha de "[...] estudar explicitamente uma série de questões (singularidade/generalidade; visão etnográfica/visão estatística; microssociologia/macrossociologia; estruturas cognitivas individuais/estruturas objetivas) a respeito de um objeto singular e limitado" (LAHIRE, 1997, p. 14). Consideramos possível aproximar essa metodologia da concepção de ecologia de saberes. A conclusão do autor coloca em destaque a influência do processo de sociabilidade como fundante do processo de aprendizagem.

Destacamos, a seguir, como a categoria sociabilidade se faz presente na tessitura do que surge como ato educativo no espaço do improvável, dentro de um movimento de questionamento epistemológico e pedagógico provocado pelo pensamento decolonial.

\section{Estar Juntos na Escola: ecologia de saberes, colonialidade e sociabilidade}

A escola é o espaço no qual o agir se dá em relação com as pessoas e não apenas no campo das ideias. $\mathrm{O}$ que consta no livro didático é uma ideia, o que se faz com isso na escola é vida. Ao fim, na escola estamos sempre a tratar de vida, a considerar a perspectiva teórico-metodológica assumida neste texto. Por isso, não se trata tão somente de um espaço de transmissão de saberes. É sempre um espaço de encontro, de compartilhamento, de sociabilidade. Temos nos equivocado em dar destaque somente para um ponto: a transmissão de saberes sistematizados e definidos como científicos. É fato que é preciso ultrapassar o senso comum em nossas escolas, mas é fato também que esse senso comum precisa ser valorizado na qualidade de saber a partir do qual a ciência se desenvolve. Esquecê-lo, deixá-lo de fora da escola é fazer do saber científico que se espera ser aprendido pelos alunos um balão de gás hélio: chega nas alturas, mas sem vínculo algum com o chão no qual o sujeito vive. 
Compreendemos por sociabilidade o conjunto de interações sociais que se estabelecem por opção do indivíduo, destacando-se seu aspecto de ludicidade e de espontaneidade. Trata-se de um tipo de socialização que tem a especificidade de afastar-se dos condicionamentos de conteúdo institucional, apresentando-se como forma de convivência grupal (2009). Fundamentando-nos na perspectiva sociológica de Georg Simmel (1983), situamos os processos de socialização dentro da cultura escolar.

Nos espaços escolares constroem-se processos de socialização que pressupõem todas as ações intencionais de adaptar o sujeito à sociedade em que vive, variando conforme as práticas cotidianas, especialmente quando ocorrem em sociedades complexas, de relações multifacetadas. No caso de uma sociedade racista, com políticas públicas afirmativas e antirracistas, o conceito de adaptação é tensionado pelo conceito de transformação (FREIRE, 1996) e de descolonização dos currículos (GOMES, 2012).

Na primeira situação em análise, destaca-se uma sociabilidade marcada pelo sofrimento resultante de proposição didática que envolve a apropriação da professora acerca de uma atividade sobre o tema do racismo num livro de História. A espontaneidade das relações, fora do ritual da aula de história, como nos intervalos, pátios e corredores, deixa transbordar vivências de discriminação racial que fazem um menino evitar esse convívio grupal. Desatacamos que, naquele momento, não tínhamos ainda as políticas curriculares de obrigatoriedade da Educação das Relações Étnico-Raciais, do ensino das histórias e culturas africanas, afro-brasileiras e indígenas. Como hoje, vivíamos o racismo nas relações cotidianas e a escola manifestou-se como lócus social dessas interações sociorraciais.

$\mathrm{Na}$ segunda abordagem de pesquisa, ressalta-se a sociabilidade marcada por relações positivadas de afetos, capazes de construir a narrativa de uma escola onde se aprende e onde se encontra momentos de reconhecimento, alegria e autoestima positivada.

Esses dados entrecruzados apontam para a complexidade do que chamamos de cultura escolar, uma vez que envolve esse estar juntos, próprio das interações sociais desenvolvidas no interior das instituições educativas.

O pensamento decolonial é premissa de nossas observações, na medida em que a instituição escolar, lócus de nossos estudos, é compreendida no contexto da colonialidade do poder e do saber (QUIJANO, 2005). Tal contexto é condicionado pelo desenvolvimento do capitalismo e da globalização, mas está em relação direta com as experiências históricas da modernidade, das quais a escola é herdeira direta. No Brasil, essa modernidade capitalista apresenta problemas específicos demarcados pela concentração de renda e pela desigualdade social e racial. Consideramos a relação entre o racismo e a hegemonia de uma visão única 
de mundo, expressa na colonialidade, no eurocentrismo e na branquitude (BENTO, 2002), característicos da produção do conhecimento científico e escolar na modernidade.

Indagar sobre esse contexto de produção do saber requer o reconhecimento da existência de um conjunto de saberes não representados nessa única visão de ciência disseminada hegemonicamente na escola e nos manuais escolares. No caso da educação antirracista, como política pública, ressalta-se analiticamente a categoria descolonização dos currículos, conforme Nilma Lino Gomes (2012), pela valorização dessas culturas locais e epistemologias diversas, vinculadas aos saberes das comunidades indígenas e negras.

Ao nos determos nos aspectos e movimentos que compõem a cultura escolar, são vários os acontecimentos que, existentes e enraizados no cotidiano da escola, não nos saltam aos olhos como objeto de investigação, porque são considerados ou como temas periféricos ou como temas subjetivos demais para contribuir na compreensão de um espaço tão complexo como é a escola. Ao nos propormos desver esse modelo de escola, lançando o olhar para o que, a princípio, não vemos, é possível construir abordagens investigativas que tenham a ideia de ecologia de saberes como base epistemológica. Por esse caminho podemos nos aproximar da provocação, ou desafio, lançado por Gimeno Sacristán (2005, p. 212) ao questionar se "nossas escolas podem ser diferentes de como são?” e o quanto ainda temos ou quanto "perdemos a capacidade de imaginá-las de outra forma”.

Pensar a escola a partir da ecologia de saberes é assumir o compartilhamento de saberes a partir do princípio da decolonialidade. Um dos saberes que são invisibilizados no processo de escolaridade é a sociabilidade, a aprendizagem de saberes que nos propiciem viver juntos. Que saberes são construídos para além da gramática estabelecida nos rituais escolares, dentro das aulas e dos manuais escritos ou dos currículos prescritos? Viver juntos pressupõe compartilhamento e se difere de estar próximos, dividindo o mesmo espaço, por exemplo, uma sala de aula. Compartilhar traduz a ideia de que cada um tenha algo, a partir de sua bagagem, de sua história de vida, para contribuir na partilha. Ao pensarmos como, o que, com quem e por que compartilhamos saberes é possível desver e encontrar o que se esconde no caso do menino negro convidado por uma professora a corporificar o racismo ao declamar os versinhos racistas colocados no livro didático. Ao analisar o fato pelo viés da sociabilidade, o que se tem é um jovem que, posto nessa situação, vê-se em rompimento com laços de sociabilidade.

Para compreender experiências como essas, precisamos repensar a relação entre as categorias raça e classe, assim como a determinação de uma sobre a outra. Nossa análise aponta para uma interseccionalidade entre essas categorias, raça e classe, observando que, nesse entrecruzamento 
analítico, sublinhamos reivindicações historicamente vinculadas à escolarização da população negra e suas consequências para as políticas públicas.

A seguir, aprofundaremos um pouco os dados produzidos em cada investigação, para finalizar com algumas considerações possíveis a partir das categorias escolhidas na análise desses dados.

\section{Versos e Reversos: discriminação racial ou afetos positivados como modos distintos de estar juntos}

Diz-se correntemente que o racismo é uma chaga da humanidade. Mas é preciso que não nos contentemos com essa frase. É preciso procurar incansavelmente as repercussões do racismo em todo os níveis de sociabilidade (FANON, 1969, p. 40).

Direcionamos nossa escrita para a situação enumerada como primeira e que analisa um modo de estar junto demarcado pela presença da discriminação racial, ou seja, uma sociabilidade causadora de sofrimentos e rompimentos.

Destacamos que se trata de uma história a ser fruída e compreendida em seus paradoxos e complexidades. Retornamos ao episódio vivido, no tempo presente, na forma de uma investigação no campo da pesquisa em Educação, entendendo-o como um processo inacabado, exatamente pelo seu vínculo com uma temática socialmente viva: o racismo. Não desejamos julgar decisões de vida de sujeitos sociais no passado, mas refletir criticamente sobre os contextos que envolveram suas experiências e as subjetividades ou saberes nelas imbricados.

No ano de 1997, no estado do Paraná, foi impetrado um processo de denúncia pública referente à presença de racismo numa coleção didática de História. A obra em questão é a coleção para o ensino fundamental intitulada Brasil: Uma história em construção, foi publicada pela Editora do Brasil SA, no ano de 1996. O processo foi instaurado pela Associação União e Consciência Negra de Maringá (PR), em 1997, sendo encaminhado à Promotoria Especial de Defesa do Consumidor, Meio Ambiente e Garantias Constitucionais, pertencente à Promotoria de Justiça da Comarca de Maringá do Ministério Público do Estado do Paraná, com alegação de evidências de discriminação racial no capítulo IX do volume 1 da referida coleção, seguida de solicitação da retirada da obra didática das escolas. Destaca-se que, naquele ano, a coleção fora adquirida e distribuída pela Secretaria Estadual de Educação para uso obrigatório nas aulas de História da rede pública estadual. Com o evento da denúncia, Secretaria Estadual de Educação, autores e Editora foram intimados a comparecer em audiências públicas. Tais negociações resultaram num acordo que levou à modificação de duas páginas da 
obra, respectivamente 80 e 81 , nas quais constavam as atividades alvo da ação judicial descritas anteriormente. No contexto dessa ação judicial está a história de um menino que resistiu a cumprir a gramática da tarefa proposta pela professora, em sua apropriação da atividade sugerida pelo livro.

Vejamos trecho da entrevista concedida pelo pai, acerca da atitude improvável do menino:

Levantava cedo, ia para o Colégio. Não tinha problema nenhum. Um dia, eu chamei ele para ir ao Colégio: 'Vamos?'. Ele não quis ir. Foi meio emburrado, mas foi. No outro dia chamei de novo, mas ele foi emburrado. No terceiro dia ele pegou e me mostrou o livro: 'Pai, a professora quer que eu leia isso daí, no meio dos alunos'. Aí ficou revoltado. Daí não foi. Daí eu li essa parte. No mesmo dia eu peguei e falei: 'Vamos comigo lá no Fórum?' (Entrevista 3, Campo Mourão, 05/11/2017).

Na ocasião, a Editora contratou dois avaliadores ad-hoc para construírem pareceres sobre os livros e o suposto caráter racista que continham. Um deles foi um importante intelectual negro brasileiro, referência nos estudos sobre as questões raciais em nosso país, cujo parecer recebeu por título - Um equívoco bem-intencionado: o pedido de apreensão do livro Brasil: uma história em construção. Tais pareceres não foram utilizados, pois o episódio judicial encerrou-se num acordo de substituição das páginas referenciadas e questionadas. A Secretaria Estadual de Educação responsabilizou-se pela ação de retirar das escolas os livros, substituir as páginas e devolvê-los com tal retificação.

Observa-se que, na memória do autor do livro, a presença dos familiares do menino de Campo Mourão na audiência pública, é marcante. Sua entrevista destaca o relato de uma sequência posterior de troca de cartas com essa família. O autor revela sua surpresa com a apropriação do livro e da atividade proposta acerca do racismo, realizada pela comunidade escolar, especialmente professores e estudantes. É justamente essa apropriação, analisada a partir das categorias racialidade e sociabilidade, que se torna o alvo central da análise aqui empreendida.

Ressalta-se que, justamente em 1996, teve início o processo de avaliação pedagógica dos livros de História inscritos para o Programa Nacional do Livro Didático (PNLD) criado pelo Decreto ${ }^{0}$ 91.542, de 19/8/85. Em 1996, foi igualmente publicado o primeiro Guia do PNLD, com os resultados da avaliação das obras destinadas aos Anos Iniciais do Ensino Fundamental. Em 1997, a responsabilidade pela política de execução do PNLD é transferida integralmente para o Fundo Nacional de Desenvolvimento da Educação (FNDE). O Programa é ampliado e o Ministério da Educação passa a avaliar, adquirir e distribuir, de 
forma continuada, livros didáticos de Alfabetização, Língua Portuguesa, Matemática, Ciências, Estudos Sociais, História e Geografia para todos os alunos de $1^{\mathrm{a}}$ a $8^{\mathrm{a}}$ série do ensino fundamental público. Assim, em 1997 consolidouse o processo do primeiro edital do PNLD, responsável por avaliar coleções didáticas de História nos Anos Finais do Ensino Fundamental, momento em que a referida obra foi aprovada, o que significa que ela estava em consonância com o requisitado no edital. No ano de 1998, o Sindicato dos Professores das Redes Púbicas Estaduais e Municipais no Paraná enviou carta ao Ministério de Educação (MEC) solicitando esclarecimentos acerca da presença da obra na listagem de livros recomendados pelo MEC, destacando a necessidade de mudanças no conteúdo da obra ou impedimento da sua participação no Edital 1997 do PNLD, uma vez que ela supostamente divulgava ideias racistas aos estudantes. O livro foi aprovado com as páginas alteradas, conforme acordo judicial citado anteriormente.

Destaca-se que os fatos aconteceram em período anterior à criação do artigo 26-A, por meio da Lei 10.639/o3, da Lei de Diretrizes e Bases da Educação Nacional, que coloca no debate curricular nacional o projeto da Educação das Relações Étnico-Raciais e a obrigatoriedade do ensino de histórias e culturas africanas e afro-brasileiras. São igualmente anteriores à III Conferência Mundial de Combate ao Racismo, Discriminação Racial, Xenofobia e Intolerância Correlata, em Durban, África do Sul, 2001, momento em que o Estado brasileiro reconhece a existência do racismo no País e o compromisso de criar políticas reparatórias para a construção da equidade racial.

Mesmo que temporalmente deslocados, tais fatos reforçam estudos (GONÇALVES; SILVA, 2000; GOMES, 2017) capazes de comprovar a existência dessas pautas sociais e educativas como resultado das ações historicamente construídas pelo Movimento Negro em nosso país. As Ciências Humanas, em geral, e a área da Educação, em específico, foram tensionadas epistemologicamente e pedagogicamente pelas pautas do Movimento Negro, sendo tributárias dessas ações. Nossa análise se alinha ao objetivo de "[...] reconhecer e tornar credíveis os saberes produzidos, articulados e sistematizados pelo Movimento Negro para a prática e para o pensamento educacional" (GOMES, 2017, p. 137-138).

Esta breve exposição pode apontar múltiplas possibilidades interpretativas de tal fato. Buscamos respostas parciais dentro do referencial teórico acerca das especificidades do racismo no Brasil, num contexto de estruturas socioeconômicas de dominância (HALL, 2003), marcadas pela extrema desigualdade social própria do desenvolvimento das sociedades capitalistas. Tais estruturas em dominância são interseccionadas pela chave de leitura do racismo e da racialidade como centrais na concretização das relações de poder na sociedade. Em outras palavras, no caso brasileiro, o racismo estrutura as relações de poder 
nas práticas sociais vividas no cotidiano. Segundo Fanon (1969, p. 35),

[...] o surgimento do racismo não é fundamentalmente determinante. $\mathrm{O}$ racismo não é um todo, mas o elemento mais visível, mais cotidiano, para dizermos tudo, em certos momentos, mais grosseiro de uma estrutura dada.

Nossas problematizações circundam perguntas como: que sociabilidades são produzidas quando o racismo é abordado no livro e na aula de História? Como distintos atores sociais - jovens estudantes, professores, famílias, movimento negro - lidam com essas sociabilidades?

Destaca-se o fato de que o episódio em análise ganha proporções maiores diante do desejo do menino de não ir mais para a escola, o que aqui nominamos como um modo de estar junto marcado pela discriminação racial. A família lembra que foram os próprios colegas do menino que repetiam os versos, como no relato a seguir:

Daí ele falou que não queria ir para a aula [...] Por causa dos colegas. Porque sempre quem tira sarro são os colegas mais achegados da gente. Eram os próprios colegas dele tirando sarro dele (Entrevista 3, Campo Mourão, 05/11/2017).

As narrativas de distintos atores sobre o episódio rememoram que as crianças repetiam os versos e ladainhas constantes no livro didático, num tom de zombaria, em momentos como recreio, intervalos e aulas de Educação Física. Observamos que são nos ambientes de maior sociabilidade que se destacam as atitudes preconceituosas e discriminatórias, nesse caso, do ponto de vista racial. São sociabilidades marcadas pela hierarquização racial, colocando o negro em situação de desvantagem e sofrimento.

O uso ou apropriações do livro didático é um tema em interface nesse estudo e pode aqui estar relativo ao fato de que a história ensinada, como processo de mediação cultural, extrapola os muros dos saberes construídos nas escolas ou nos círculos acadêmicos. Defendemos que a prática pedagógica é prática de interação socioeducativa e acontece na dinâmica própria de cada unidade de ensino, sala de aula, envolvendo relações humanas, currículos e políticas públicas locais ou globais. Os estudantes não constroem seus saberes em relação ao conhecimento histórico somente com o adquirido nas aulas de História da escola, mas também por intermédio das variadas redes sociais que podem incluir a família, o grupo de iguais, grupos culturais, políticos, religiosos e, igualmente, através das mídias e das novas tecnologias de informação. Segundo José Gimeno Sacristán (2000, p. 43), “[...] no sentido amplo, a educação não se esgota, evidentemente, nas aulas, pois é a soma da concorrência de todos esses âmbitos socializadores". 
Ressaltamos o fato de que a Educação para as Relações Étnico-Raciais, no que concerne às abordagens das histórias e culturas africanas, afro-brasileiras e indígenas, desestabiliza não apenas o currículo a ser ensinado do ponto de vista do conteúdo histórico. Ao propor o redirecionamento da educação no que diz respeito às interações sociorraciais estabelecidas no ambiente escolar, tal projeto educativo desestabiliza o currículo do ponto de vista do ensinado na prática pedagógica. Trata-se de um movimento político-pedagógico que indaga a história ensinada acerca dos conhecimentos ou conteúdos próprios de seu campo, mas também desafia a uma posição ética e política diante das relações racistas e racializadas no cotidiano escolar. Essa posição está, em nossa compreensão, associada à possibilidade de descolonização dos currículos (GOMES, 2012), ainda carente de debate mais contínuo na comunidade acadêmica e escolar.

Seguimos com a situação de pesquisa, enumerada como segunda. Nos relatos depositados pelas crianças em forma de cartinhas, os afetos positivados como modos distintos de estar juntos se destacam como base para as aprendizagens mais significativas vivenciadas na escola. Os relatos/desenhos com conteúdo semelhante ao destacado a seguir foram agrupados em uma categoria intitulada relações humanas e dialogam de forma clara com a importância de estar junto, com a construção da identidade, processo uno e diverso pelo qual todos passamos. A referência aos estudos sobre discriminação consta em vários relatos fazendo referência ao bullying, ao respeito pelo outro. Todos esses saberes são indicados pelos alunos como momentos de sucesso na escola para aprendermos sobre o que somos e sobre os outros, ou melhor, sobre nossas concepções sobre os outros.

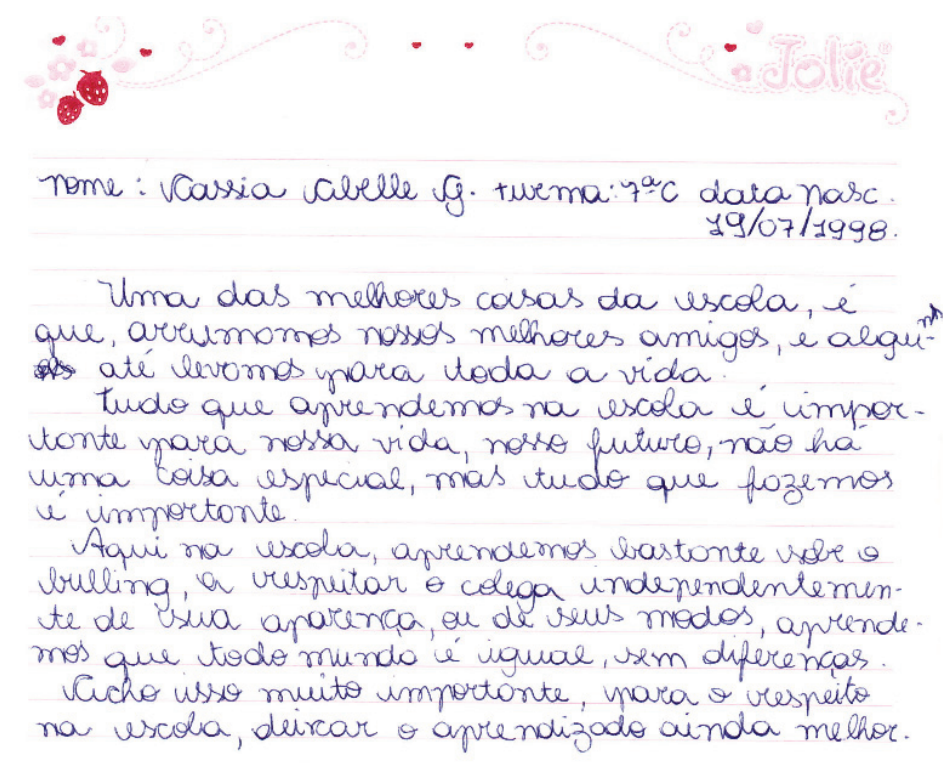

Figura 1 - Cartinha. 
Os conteúdos clássicos das disciplinas, ainda que presentes nos relatos dos alunos, não são os protagonistas das narrativas. A considerar que temos uma escola com foco em tais conteúdos, por vezes também denominados de conteúdos científicos, fica uma indagação sobre por que os alunos não conferem destaque a eles em seus relatos: será que não há uma efetiva aprendizagem de tais saberes na escola? Será que o processo de aprendizagem desses conteúdos é por demais dificultoso para explicitar uma experiência de sucesso na escola? No relato anterior, a aluna indica que todos os saberes apreendidos na escola são importantes para a vida e prossegue argumentando sobre a importância do respeito ao outro, e como um ambiente no qual essa relação se estabeleça favorece ainda mais o aprendizado. A resposta da aluna, que é representativa de um conjunto de manifestações com a mesma tipologia, nos leva a considerar que se trata de um desafio premente reavaliar o que se seleciona para ser ensinado nas escolas e que intitulamos como conteúdos.

A palavra gostar, ainda que não tenha sido mencionada em nenhum momento da pesquisa, é bastante utilizada pelos alunos dos diferentes anos de escolaridade. A relação entre o sucesso pedagógico e o gostar do que se aprende ou do que se vivencia na escola foi construída pelos alunos e demonstra uma mistura de elementos e nos remete a pensar sobre o espaço da afetividade na escola. A leitura das oito centenas de relatos indica que, ao fazer referência ao gostar, o aluno remete à ideia de se sentir bem ao lado do outro, de responsabilidade e respeito entre todos. Uma espécie de cuidado de todos para com todos e, em meio a tudo isso, elaboram-se os mais diversos tipos de conhecimento.

Pode-se considerar que os professores foram receptivos ao projeto, a maioria da área de Ciências Humanas, outros nem tanto. Vários demonstraram incredulidade sobre os alunos identificarem e relatarem situações de sucesso na escola e ficaram surpresos quando tomaram conhecimento do resultado. Quanto aos professores, o objetivo da pesquisa foi entender quais são os princípios pedagógicos que sustentam uma experiência bem-sucedida, qual o contexto que favorece o desenvolvimento dessas experiências, se podemos falar de um perfil de professor que desencadeia essas experiências e se há possibilidades de identificarmos diferentes concepções do que seja aprender e de como se aprende.

Ao responderem sobre o que entendem por sucesso pedagógico, os professores, em sua maioria, afirmaram que se obtém sucesso na escola quando a aprendizagem é significativa para os alunos, quando tais aprendizagens se tornaram tatuagem, quando ultrapassam também a sala de aulas e podem ser consideradas exitosas porque as crianças acreditam que são produtoras de conhecimento. Produzem conhecimento. Se tornam mais confiantes. 
Para além do conhecimento científico em si, todos os professores relataram sobre experiências que se baseiam na liberdade de falar e de ouvir dos alunos, no despertar de seu senso crítico desde os primeiros anos de escolaridade e no envolvimento com trabalho em projetos. Segundo eles, essas experiências criam a identidade da escola, daquele corpo docente em questão, e o sucesso escolar é obtido quando toda a comunidade escolar trabalha em conjunto para alcançar um objetivo comum, que é proporcionar uma educação de qualidade para os alunos que ali estão. A considerar as análises dos professores, pode-se definir que uma situação de sucesso escolar é aquela que incita e valoriza as relações humanas desenvolvidas em diferentes espaços, principalmente para além da sala de aula, e de diferentes formas, na qual o professor assume a responsabilidade de ensinar conhecimentos que possibilitam compreender os problemas atuais.

Ao elegermos como foco investigativo casos específicos de sucesso pedagógico selecionados pelos próprios sujeitos envolvidos, e ao ampliarmos nossa compreensão sobre os casos evidenciados abordamos, de outra perspectiva, as possíveis causas do fracasso escolar. Reafirma-se, assim, a importância de determo-nos em pesquisas que focalizem os professores e os alunos a partir de como estão no cotidiano escolar e não a partir de suposições de como são ou deveriam ser ao desempenharem suas funções na escola. A princípio, considerando uma abordagem improvável, o estudo sobre as histórias de sucessos de alunos e professores nos possibilitou tecer várias interpretações para a heterogeneidade na tríade professor, aluno e saber. Em meio a tamanha diversidade, há dois aspectos a serem destacados a título de conclusão: primeiro, para além do conhecimento científico em si, todos relatam sobre experiências que se baseiam na liberdade de falar e de ouvir no espaço escolar. Segundo, as histórias abordam ações que fomentam a identidade do sujeito - aluno ou professor, e a identidade da escola, sugerindo que situações de sucesso escolar são conquistadas quando toda a comunidade escolar trabalha em conjunto para alcançar um objetivo comum, que é proporcionar uma educação de qualidade para os alunos que ali estão.

\section{Considerações Finais}

Este ensaio resultou do desejo das autoras de colocar a escola sob uma nova mirada, focalizando o olhar em alguns elementos da cultura escolar que, por serem considerados ordinários, cotidianos, insignificantes, são banalizados na rotina da escola. Movidas pela suspeita de que sob esses feitos rotineiros subjaz um sistema estruturado de sociabilidades, mergulhamos em duas práticas investigativas que oferecem indícios para compreender um pouco do que ocorre entre os muros da escola, o que se passa entre as paredes das salas de aula, quais práticas são criadas 
e reinventadas pelos sujeitos na dinâmica do estar junto, que confirmam ou que transgridem a chamada gramática da escolarização (BENITO, 2017).

Para viver juntos na escola, professores e alunos vão criando seus próprios modos de estar juntos. Em geral, buscam se acomodar às regras estabelecidas pela tradição ou pelos costumes e internalizam ritos à medida que se incorporam à comunidade educativa, ao longo dos anos de escolarização. São ações corriqueiras, como sentar-se em uma carteira individual enfileirada, ouvir a exposição do(a) professor(a), fazer cópias do quadro, escrever em seus cadernos, ler e responder exercícios no livro didático, erguer a mão para falar, dentre tantas outras. Esses são ritos visíveis, que saltam aos olhos até do observador mais desatento. Mas ali também ocorrem situações menos visíveis, que são da ordem dos sentidos, das significações, dos silêncios, dos não-ditos, etc., que compõem as distintas sociabilidades do/no estar junto na sala de aula.

É sobre esse segundo conjunto de sociabilidades que nos debruçamos. Trata-se de sociabilidades marcadas pela diversidade de sujeitos e práticas que se encontram na sala de aula e que impõem o enfrentamento de situações sensíveis e de temas socialmente vivos, que teimam em desafiar a gramática escolar, como, por exemplo, as sexualidades, as racialidades, as religiosidades, as violências, as migrações, as questões ambientais, dentre outros.

No caso do primeiro movimento de pesquisa tratado neste ensaio, em que ao estudante negro foi solicitada a leitura de trechos do livro didático que ensejam interpretações racistas, ali estavam presentes alguns dos elementos triviais da dinâmica da sala de aula, já mencionados. Mas o improvável aconteceu, uma vez que o jovem não se sujeitou aos ritos estabelecidos, gerando um conflito que extrapolou as paredes da sala de aula e os muros da escola, chegando a um processo de judicialização das relações escolares. Com uma instigante metáfora dramatúrgica, Benito (2017, p. 81) analisa as representações da vida escolar e mostra que, embora seja no proscênio que se executa o ritual, as chaves de leitura estão atrás das cenas. Diz o autor: "[...] por trás das bambolinas do teatro visível da classe, ocultam-se os dramas subjetivos vivenciados pelos atores, os quais, não obstante, podem ser trazidos à cena, para sua abordagem lúdico-representativa".

O episódio trazido nesse primeiro movimento de pesquisa evidencia um desses dramas subjetivos, um caso exemplar em que o silêncio foi rompido pela impossibilidade de um estudante suportar aquele modo proposto de estar junto na escola. Mas não se trata deste estudante, desta professora, desta escola. Trata-se da tradição de uma cultura escolar que, como assinala Tereza Punta (2016, p. 12), encontra grandes dificuldades em "[...] construir continentes capazes de alojar as formas diversas e assistemáticas das nossas crianças, de suas histórias”, ou, ainda, de entender que a escola é feita de muito mais que 
conhecimento, sobretudo, ela é constituída de experiências subjetivas e amorosas.

Então nos reportamos ao segundo movimento investigativo, que se debruça sobre os relatos/desenhos das histórias escolares de sucesso de estudantes do ensino fundamental. As cartinhas das crianças e jovens evidenciam que o estar junto na escola não diz respeito tão somente aos processos formais de instrução, ou apenas à aprendizagem dos chamados conteúdos escolares, embora não se trate de destituir o valor dos conhecimentos científicos que se traduzem em saberes escolares. O que se propõe aqui é pensar possibilidades para uma escola que rompa com a hierarquia de saberes, que questione a hegemonia do conhecimento científico, que possa vislumbrar caminhos por uma ecologia de saberes, como ensina Santos (2002).

Um dos caminhos possíveis seria revisar os desenhos curriculares e inventar, coletivamente, novos modos de ensinar e de aprender, novos modos de estar juntos, reconhecendo que nem todos necessitam das mesmas coisas ao mesmo tempo. Na perspectiva de Punta (2016, p. 39), isso exigiria pensar o currículo como um texto aberto e inacabado, em que não se defina previamente que os alunos aprendem do próximo ao distante, do simples ao complexo e, mais do que isso, em que não se determine de antemão o que é complexo, sem que se tenha ideia das complexidades nas quais navegam as crianças. Ainda, uma escola com um desenho curricular que promova o encontro das subjetividades, das diferenças, dos afetos, pois, "se na escola não se dá o encontro, não há escola” (PUNTA, 2016, p. 52). Por fim, uma escola que não negue o outro em sua outridade (PUNTA, 2016, p. 61) e que não atue no sentido de restringir o universo amplo de sociabilidades que podem ser construídas no cotidiano escolar, pautando o respeito e a amorosidade como modos fundamentais de estar juntos.

\section{Referências}

BENITO, Agustín Escolano. A Escola como Cultura: experiência, memória e arqueologia. Campinas, SP: Editora Alínea, 2017.

BENTO, Maria Aparecida da Silva. Branqueamento e branquitude no Brasil. In: Psicologia social do racismoestudos sobre branquitude e branqueamento no Brasil. Iracy Carone, Maria Aparecida Silva Bento (Orgs.). Petrópolis, RJ: Vozes, p. 25-58, 2002.

BRASIL. Conselho Nacional de Educação. Parecer CNE/CP n. 003/2004 de 10 de março de 2004. Diretrizes curriculares nacionais para a educação das relações étnico-raciais e para o ensino de História e Cultura Afro-brasileira e Africana. Diário Oficial da União, Brasília, DF, 19 maio 2004. 
CHOQUEHUANGA, David. Hacia la reconstrucción del Vivir Bien. América Latina en Movimiento, Quito, Agencia latinoamericana de Informacion (Alai), n. 452, p. 6-13, 2010.

FANON, Frantz. Em Defesa da Revolução Africana. Lisboa: Livraria Sá da Costa, 1969.

FREIRE, Paulo. Pedagogia da Autonomia. 2. ed. São Paulo: Paz e Terra, 1996.

GIMENO SACRISTÁN, José. A Educação Obrigatória: o seu sentido educativo e social. Porto: Porto Ed., 2000.

GOMES, Nilma Lino. Relações étnico-raciais, educação e descolonização dos currículos. Currículo sem Fronteiras, v. 12, n. 1, p. 98-109, jan./abr. 2012.

O Movimento Negro Educador: saberes construídos nas lutas por emancipação. Petrópolis: Vozes, 2017.

GONÇALVES, Luiz Alberto Oliveira; SILVA, Petronilha Beatriz Gonçalves e. Movimento Negro e Educação. Revista Brasileira de Educação, Rio de Janeiro, n. 15, p. 134-158, set./dez. 2000.

HALL, Stuart. Da Diáspora: identidades e mediações culturais. Belo Horizonte: Editora UFMG; Brasília: Representação da UNESCO no Brasil, 2003.

LAHIRE, Bernard. Sucesso Escolar nos Meios Populares: as razões do improvável. São Paulo: Ática, 1997.

MACEDO, José Rivair; OLIVEIRA, Mariley W. Brasil: uma história em construção. São Paulo: Editora do Brasil, 1996. Volume 1.

MIÉVILLE, China. A cidade \& a cidade. São Paulo: Boitempo. 2014.

NOGUERA, Fernando. Filosofando com Sotaques Africanos e Indígenas. Portal da ANPOF, 20 de fevereiro de 2017. Disponível em: <http://anpof.org.portal/ index.php/en/comunidade/coluna-anpof/1089-filosofando-com-sotaques-africanos-e-indigenas $>$. Acesso em: 30 maio 2018.

ORGANIZAÇÃO DAS NAÇÕES UNIDAS. Declaração e Programa de Ação. Conferência Mundial de Combate ao Racismo, Discriminação Racial, Xenofobia e Intolerância Correlata. Durban, África do Sul, 2001.

PIAGET, Jean. Abstração reflexionante. Porto Alegre: ARTMED. 1995

PUNTA, Teresa. Señales de Vida: uma bitácora de escuela. Buenos Aires: Lugar Editorial, 2016. 
QUIJANO, Aníbal. Colonialidade do poder, Eurocentrismo e América Latina. In: A colonialidade do saber: eurocentrismo e ciências sociais. Perspectivas latino-americanas. CLACSO, Consejo Latinoamericano de Ciencias Sociales, 2005.

RATTERO, Carina (Comp.). La Escuela Inquieta: explorando nuevas versiones de la enseñanza y del aprendizaje. Buenos Aires: Noveduc, 2013.

SANTOS, Boaventura de Sousa. Para uma sociologia das ausências e uma sociologia das emergências. Revista Crítica de Ciências Sociais, Coimbra, v. 63, p. 237-280, 2002.

; MENESES, Maria Paula. Epistemologias do Sul. São Paulo: Cortez, 2010.

SANTOS, Boaventura de Sousa. Para além do pensamento abissal: das linhas globais a uma ecologia de saberes. In: SANTOS, Boaventura de Sousa; MENESES, Maria Paula. Epistemologias do Sul. São Paulo: Cortez, 2010. p. 23-71.

SIMMEL, Georg. Sociabilidade: um exemplo de sociologia pura ou formal. In: MORAIS FILHO, Evaristo (Org.). Simmel. São Paulo: Ática, 1983. (Coleção Grandes Pensadores). P. 165-188.

Recebido em: 28/07/2018 Aprovado em: 18/12/2018 Publicado em: 31/12/2018 